\title{
Hospitalists and Primary Care
}

\author{
David O. Meltzer, MD, PhD
}

Department of Medicine Section of Hospital Medicine, Harris School of Public Policy Studies, and the Department of Economics, The University of Chicago, Chicago, IL, USA.

$J$ Gen Intern Med 30(5):541-2

DOI: $10.1007 / \mathrm{s} 11606-015-3246-1$

(c) Society of General Internal Medicine 2015

$\mathrm{T}$ he article by Park and Jones ${ }^{1}$ in this issue of JGIM focuses on the potential for primary care physicians (PCPs) to increase the number of primary care visits they can provide when they rely on hospitalists to care for their patients in the hospital. To the extent that seeing hospitalized patients requires time within a fixed workday, this result seems almost inevitable. Nevertheless, the finding of Park and Jones that PCPs who have at least $75 \%$ of their hospitalized patients cared for by hospitalists see about nine more patients in clinic per week provides a valuable estimate of the magnitude of these effects, which constitute about $10 \%$ of the average visit volume of a full-time PCP.

Park and Jones focus on the potential implications of this finding for the primary care workforce. They estimate that among the one-third of PCPs in the US who have at least $75 \%$ of their patients cared for by hospitalists, using hospitalists frees up about 7,000 full-time equivalents (FTEs) of PCP effort. This is a large amount of effort, and the authors extrapolate that if the use of hospitalists increased to these levels for the other two-thirds of PCPs, a great deal of their time would be freed up for primary care. However, as the authors also note, it is unclear if having more hospitalized patients cared for by hospitalists would increase the availability of primary care, because this change would require increasing numbers of hospitalists, who would almost certainly come out of the same ranks of general internists and physicians in other specialties who might otherwise provide primary care.

I think the paper by Park and Jones is important not primarily because it suggests a possible approach to increase the primary care workforce; there is too much potential for the growing use of hospitalists to further drain the primary care workforce, and especially to the extent that their effort is used to reduce inpatient work by medical subspecialists rather than PCPs. Instead, I think the paper is important because it adds to the growing literature on why the use of hospitalists has grown and suggests next generation models that may better serve patients. In prior work published in JGIM and elsewhere, Jeanette Chung and I have argued that the use of hospitalists increased because they allow PCPs to be able to see more

Published online March 3, 2015 primary care patients, and also avoid costly trips to the hospital to see their hospitalized patients. ${ }^{2-4}$ Our results are supported both by microeconomic models of physician time allocation and by empirical evidence, which is corroborated by a notable finding of Park and Jones, that male physicians are less likely to use hospitalists than are female physicians. In our analysis, this finding is thought to be explained by the greater number of hours typically worked by male as opposed to female physicians, making a daily trip to the hospital to see patients more likely to be feasible and economically viable.

An important caution in interpreting the paper by Park and Jones is the suggestion that PCPs are more productive when they focus only on primary care. Caution here should be twofold. First, the paper does not directly evaluate whether the time lost in primary care when PCPs use hospitalists would be smaller or larger than the time lost to primary care when more potential PCPs become hospitalists rather than entering primary care. In other words, the workforce effect (in which more potential PCPs choose to become hospitalists) may be either larger or smaller than the substitution effect (in which primary care physicians are freed up to see more outpatients). Second, productivity can be assessed only when the value of the activity is measured, and data on how having primary care patients see their own patients in the hospital affects costs and outcomes remains sorely lacking.

This comment may surprise some who are aware of the myriad papers examining the costs and outcomes of patients cared for by hospitalists and non-hospitalists over the past 20 years. However, there are still no randomized controlled trials (RCTs) that compare the outcomes of care by hospitalists to care by PCPs who care for their own patents in the inpatient and outpatient setting. Instead, the comparison group for hospitalists in the published studies of hospitalists that rely on random assignment is doctors who are not the patient's PCP, but just have less inpatient volume or experience than hospitalists. As a result, the literature on hospitalist outcomes tells more about the effects of inpatient volume and experience ${ }^{5}$ than it tells us about the effects of moving from a traditional model of combined inpatient and outpatient care under one doctor to a model with ambulatory-based PCPs and hospitalists.

At one level, the absence of rigorous RCT data comparing the hospitalist model and the traditional model is unfortunate, as these data could inform a range of clinical and policy 
decisions. However, if the analysis by myself and Chung, as supported by the findings of Park and Jones, is correct, then the decline of PCPs that see patients both in clinic and the hospital may be a largely inevitable result of the time costs of trying to work in both settings, especially as ambulatory volumes increase relative to hospital volumes, so that a daily trip to the hospital has declining economic and clinical benefits relative to costs. Given the rich evidence to support the value of continuity in the doctor-patient relationship, ${ }^{6-9}$ it is plausible that patient benefits or health system savings would be large enough to overcome this economic pressure but it seems unlikely we will ever know this for certain.

At another level, the absence of such data comparing the hospitalist model to the traditional model is less concerning, as there may be models of care that are better for important groups of patients. One model that we have been examining is what we call the Comprehensive Care Physician (CCP) model. ${ }^{10}$ In this model, patients at increased risk of hospitalization receive care from the same physician in the inpatient and outpatient setting. The CCPs are able to care for these patients in both settings, because they focus their practice on a small panel of $<200$ patients at high risk of hospitalization, so that their clinic volumes are low enough that they can spend each morning seeing their own patients in the hospital, while the acuity of their panel is high enough that they consistently have enough hospitalized patients to justify their daily presence there even with their small panel size. We are currently evaluating the CCP model at the University of Chicago through a randomized trial funded by the Center for Medicare and Medicaid Innovation, with results expected within 2 years. Whereas movement of potential PCPs into hospital medicine may well fail to improve access to primary care, and may even worsen it, movement of hospitalists or new residency graduates who would otherwise become hospitalists into the
CCP model would be very likely to increase access to primary care, especially for patients at increased risk of hospitalization who may be in greatest need of improved access to primary care by physicians.

Corresponding Author: David O. Meltzer, $M D, P h D$; Department of Medicine Section of Hospital Medicine, Harris School of Public Policy Studies, and the Department of Economics The University of Chicago, 5841 S Maryland MC 5000, Chicago, IL 60637, USA (e-mail:dmeltzer@medicine.bsd.uchicago.edu).

\section{REFERENCES}

1. Park J, Jones $\mathbf{K}$. Use of hospitalists and office-based primary care physicians' productivity. J Gen Intern Med. doi:10.1007/s11606-014-3007-6.

2. Meltzer DO, Chung JW. US trends in hospitalization and generalist physician workforce and the emergence of hospitalists. Journal of General Internal Medicine. 2010;25(5):453-459. PMC2855010.

3. Meltzer D. Hospitalists and the doctor-patient relationship. J Legal Stud. 2002;30(2):589-606. Part 2, PMID: 12647747

4. Meltzer D, Chung $\mathbf{J}$. Coordination, switching costs and the Division of Labor in general medicine: an economic explanation for the Emergence of Hospitalists in the United States. The National Bureau of Economic Research Working Paper Series. \#16040 May 2010.

5. Meltzer D, Manning W, Morrison J, Shah M, Jin L, Guth T, Levinson W. Effects of physician experience on costs and outcomes on an academic general medicine service: results of a trial of hospitalists. Annals of Internal Medicine. 2002;137:866-874. PMID: 12458986.

6. Murphy J, Chang H, Montgomery JE, Rogers WH, Safran DG. The quality of physician-patient relationships:patients' experiences 19961999. J Fam Pract. 2001:50(2):123-9.

7. Gill JM, Mainous AG 3rd. The role of provider continuity in preventing hospitalizations. Arch Fam Med. 1998;7(4):352-7.

8. Weiss LG, Blustein J. Faithful patients: the effect of long-term physicianpatient relationships on the costs and use of health care by older Americans. Am J Public Health. 1996;86(12):1742-7.

9. Wasson JH, Sauvigne AE, Mogielnicki RP, Frey WG, Soc $\mathbf{C H}$, Gaudette C, et al. Continuity of outpatient medical care in elderly men. A randomized trial. JAMA. 1984;252(17):2413-7.

10. Meltzer DO, Ruhnke G. Redesigning care for patients at increased hospitalization risk: the comprehensive care physician model. Health Affairs. 2014;33(5):770-77. 